\title{
Identification of Predictors of Abnormal Calcium, Magnesium and Phosphorus Blood Levels in the Emergency Department: A Retrospective Cohort Study
}

This article was published in the following Dove Press journal:

Open Access Emergency Medicine

\author{
Antoine Lapointe' \\ Nikyel Royer Moreau' \\ David Simonyan ${ }^{2}$ \\ François Rousseau ${ }^{2}$ \\ Viviane Mallette ${ }^{\text {I }}$ \\ Frédérique Préfontaine-Racine ${ }^{\prime}$ \\ Caroline Paquette' \\ Myriam Mallet ${ }^{2}$ \\ Annie St-Pierre ${ }^{1}$ \\ Simon Berthelot $\mathbb{D}^{1,2}$ \\ 'Département de médecine familiale et \\ de médecine d'urgence, Université Laval, \\ Québec, Canada; ${ }^{2}$ Centre de recherche \\ du CHU de Québec - Université Laval, \\ Québec, Canada
}

Correspondence: Antoine Lapointe Département de médecine familiale et de médecine d'urgence, Université Laval, I050 Avenue de la Médecine, Québec GIVOA6, Canada

Tel +I 4l8-656-5245

Email Antoine.lapointe.I@ulaval.ca
Purpose: With rising healthcare costs limiting access to care, the judicious use of diagnostic tests has become a critical issue for many jurisdictions. Calcium, magnesium and phosphorus serum levels are regularly performed tests in the emergency department, but their clinical relevance have come into question. Authors sought to determine risk factors that could predict abnormal calcium, magnesium and phosphorus serum levels, as well as identify patients who may need corrective interventions.

Methods: A retrospective cohort study was conducted in two academic hospitals in Québec City. Demographic and clinical characteristics of 1008 patients who had serum calcium and/ or magnesium and/or phosphorus levels drawn by an emergency physician were collected. Multivariate logistic regression models were fitted to obtain adjusted odds ratios for each risk factor for abnormal calcium or magnesium or phosphorus blood levels, and for a required intervention.

Results: Among patients for whom calcium, magnesium and phosphorus were tested in the Emergency Department, the most significant risk factors $(\mathrm{OR}>2)$ for electrolytic abnormality were as follows: hypocalcemia - respiratory distress, diuretics (excluding loop and thiazide), anti-neoplastic medication, long QTc, chronic kidney disease (CKD); hypercalcemia - bone pain, vitamin D, hallucinations; hypomagnesemia - diabetes, corticosteroids; hypermagnesemia - poor extremity perfusion, CKD, furosemide; hypophosphatemia - seizure; hyperphosphatemia - phosphate-binders, CKD, peripheral vascular atherosclerotic disease. Of all patients tested, $3.4 \%$ received a corrective intervention initiated by the emergency physician. Predictors of intervention on an electrolyte abnormality include poor peripheral perfusion, nausea and chronic obstructive pulmonary disease (COPD).

Conclusion: Emergency physicians can potentially reduce the unnecessary testing of calcium, magnesium and phosphorus blood levels by targeting patients with high-acuity conditions or chronic comorbidities such as CKD, diabetes and COPD.

Keywords: emergency medicine, metabolic, electrolyte, biochemistry

\section{Introduction}

As rising healthcare costs limit access to care, the judicious use of diagnostic tests has become a critical issue for many jurisdictions. Unnecessary laboratory testing may have a number of negative effects at a system-level (eg, waste of limited healthcare resources) and a patient-level (eg, false-positive tests triggering inappropriate 
treatments). ${ }^{1}$ In the Emergency Department (ED), overuse of laboratory tests has also been linked to an increased length of stay. $^{2}$ National and international initiatives led by the Institut d'excellence en santé et services sociaux in Québec (Canada) ${ }^{3}$ and other leading medical societies promoting the Choosing Wisely Campaign around the world ${ }^{4-6}$ have issued specific recommendations for the judicious use of laboratory tests in clinical practice.

Calcium $\left(\mathrm{Ca}^{+2}\right)$, magnesium $\left(\mathrm{Mg}^{+2}\right)$ and phosphorus $\left(\mathrm{PO}_{4}{ }^{-3}\right)$ serum levels are regularly performed tests in the $\mathrm{ED}$, but their relevance and added value to patient care have been questioned. ${ }^{7-9}$

These three assays are ordered in up to $20 \%$ of ED patients, ${ }^{7,10}$ and their costs vary widely between jurisdictions, from USD 1.69 in the province of Québec (Canada) ${ }^{11}$ to USD 26.62 in Australia and USD 96.00 in the United States of America. ${ }^{12}$ With over 3.4 million ED visits per year in the province of Québec, this represents an estimated annual expenditure of over USD $340000 .^{13}$ No specific guidelines address the clinical indications for ordering these tests and their use may partly be driven by non-medical motives, ${ }^{14}$ such as fear of litigation, ${ }^{15}$ patient pressure, and a lack of time to rationalize the tests. ${ }^{14}$ The most frequent signs and symptoms of abnormal calcium, magnesium or phosphorus serum levels are related to cardiovascular, neurologic and musculoskeletal systems, but any system can be involved. ${ }^{16}$ As such, the medical history and physical examination have a low specificity for electrolyte abnormalities, and considering that significantly abnormal electrolyte levels can be life threatening, it is not always obvious when physicians should order these tests.

Our hypothesis is that certain clinical features (eg, altered mental status) or comorbidities (eg, chronic kidney disease) predict abnormal test results and if an intervention is needed. We sought to identify these features and risk factors that predict abnormal calcium, magnesium and phosphorus serum levels, and the need for corrective interventions.

\section{Methods}

\section{Design and Study Population}

We conducted a retrospective cohort study of patients 18 years and older who had serum calcium and/or magnesium and/or phosphorus levels requested by an emergency physician, in the ED of two hospitals in Québec City, between January $1^{\text {st }} 2016$ and May $1^{\text {st }} 2016$.

The "Centre hospitalier de l'Université Laval" (CHUL) is a tertiary care center in pediatrics and provides acute general care to the adult population. The "Hôtel-Dieu de Québec" (HDQ) provides specialized care in oncology and nephrology. Respectively, around 46,000 and 21,000 adult patients seek care in these EDs each year. Both hospitals are sites of the CHU de Québec-Université Laval, the third-largest academic healthcare institution in Canada.

\section{Data Collection}

Demographic (age, sex) and clinical (comorbidities, medication, vital signs, presenting complaint, symptoms, physical exam findings, ECG findings, laboratory results, clinical intervention) characteristics were manually extracted by 6 evaluators from electronic patient records using a standardized Excel report form. The Canadian Emergency Department Information Systems presenting complaint list (version 1.1) was used to classify the reasons for visiting the ED. ${ }^{17}$ Accompanying signs and symptoms were collected based on their potential association with calcium, magnesium and phosphorus abnormalities, as identified with a literature review. ${ }^{16,18}$ Supplementary File A1 presents the legend for the variables collected. At the beginning of data collection, we measured a Kappa score, a coefficient aiming to measure interobserver reliability for categorical values, for 10 patientfiles each charted by all evaluators. A median Kappa of 1 (IQR: $0.7 ; 1)$ reflecting substantial to almost perfect interobserver agreement was obtained, and any individual data where the kappa statistic was lower than 0.6 was further discussed to ensure standardization. To ensure quality of data extraction between evaluators, the first author coordinated data collection. Any missing data for each patient file was also recorded in the Excel report form.

\section{Outcomes}

The primary outcome was the identification of predictive factors for abnormal calcium, magnesium or phosphorus serum level in the ED. We defined "abnormal" as any test value falling outside the reference range predefined by local institutional laboratories for each electrolyte (Supplementary File A2).

Secondary outcome measures were 1) the proportion of targeted therapeutic interventions following abnormal calcium, magnesium or phosphorus serum levels; and 2) the identification of predictive factors of the need for such interventions. A targeted therapeutic intervention was defined as any of the following:

- For a depleted electrolyte: per os (po) or intravenous (iv) supplementation 
- For an electrolyte in excess: stopping electrolyte supplementation, iv hydration, loop diuretic, hemodialysis or peritoneal dialysis

- Specific to hypercalcemia: po or iv bisphosphonate, calcitonin, corticosteroid, emergent parathyroidectomy or iv phosphate

- Specific to hypermagnesemia: calcium gluconate (life-threatening magnesium toxicity)

- Reference to a family physician or a specialist, as an inpatient or outpatient, because of an abnormal calcium, magnesium or phosphorus serum level.

\section{Sample Size}

A sample size of 713 observations was sufficient to detect an odds ratio of 2.0 and achieve $80 \%$ power at $5 \%$ significance level in a univariate logistic regression model. A sample size of 950 observations was adequate for a multivariate logistic regression model with $25 \%$ of $\mathrm{R}$-Squared due to confounding factors. The parameters for this estimation ( $10 \%$ of abnormality and $25 \%$ of comorbidity or symptom prevalence) were issued from a pilot study of 63 patients where prevalence of abnormality ranged from $3.0 \%$ to $11.9 \%$ and prevalence of diabetes was $25 \%$. The sample size was estimated using PASS 13 Power Analysis and Sample Size Software (2014, NCSS, LLC. Kaysville, Utah, USA).

\section{Statistical Analysis}

Continuous variables were reported as means with $95 \%$ confidence intervals, and dichotomic and categorical variables as frequencies and proportions. $F$-test, Wilcoxon rank sum and Kruskal-Wallis tests were used when appropriate for continuous data comparisons; Pearson Chi-squared or Fisher exact tests were used for categorical data. Normality of distribution has been verified to perform parametric or non-parametric bivariate tests. Multivariate stepwise logistic regression models were fitted for comorbidities, medication, presenting complaints, findings on clinical examination and other test results to obtain adjusted odds ratios for each risk factor of a calcium or magnesium or phosphorus abnormality, and for a corrective intervention. The classical stepwise-forward selection algorithm was applied in all our logistic models with a 0.05 p-value cutoff for entered into and removed from the model. The algorithm was stopped when no further effect could be added. Multicollinearity was verified before all multivariate regression models: all variance inflation coefficients were $<10$ for all analyses. Statistical analyses were performed using SAS Statistical Software v.9.4 (SAS Institute, Cary, $\mathrm{NC}$, USA), and a value of $\mathrm{P}<0.05$ was considered as statistically significant.

A waiver of consent was approved by the CHU de Québec-Université Laval Research Ethics Board (Nagano no. 2017-3104).

\section{Results}

A total of 1008 patients were included from hospital databases. Of these, 476 (47.2\%) were from the CHUL and $532(52.8 \%)$ from HDQ. Table 1 shows their baseline characteristics. Patients were not particularly elderly (mean age of 65 years old) but had a significant number of comorbidities, as evidenced by their elevated Charlson index score: fifty-four percent of patients in our whole cohort had a score of $\geq 5$ (estimated survival at 10 years of less than $21 \%$ ), while only $16.2 \%$ had a score of 0 (estimated survival at 10 years of $98 \%$ ).

Serum levels of calcium, magnesium and phosphorus were concomitantly tested $93 \%$ of the time. A selective approach was seldom used, as only $4.4 \%$ and $2.6 \%$ of patients had one or two electrolytes ordered, respectively.

Table 2 reports the prevalence of each electrolytic abnormality. Except for hypercalcemia, all abnormal levels were more prevalent in patients from the reference centre for oncology and nephrology. Of the 1008 study patients, 436 received at least one abnormal test result: 301 (29.9\%) had a single electrolyte abnormality and 135 (13.5\%) had 2 or more. Multiple abnormal results were also more prevalent in the specialized center than the general hospital (17.3\% and $9.2 \%$, respectively).

Table 3 shows the most frequent presenting complaints and signs in patients for which serum levels of calcium, magnesium or phosphorus were ordered. Neurological (eg, weakness) and gastro-intestinal (eg, nausea) manifestations were reported by $65.1 \%$ and $47.3 \%$ of all included patients.

Predictive factors of patients with abnormal electrolyte levels were identified from multivariate analyses (Table 4 and Supplementary File A3). The random effect of hospital was tested using multilevel logistic models and rejected for all abnormalities. Among all comorbidities assessed, chronic kidney disease (hypocalcemia, hypermagnesemia and hyperphosphatemia), diabetes (hypomagnesemia), alcohol abuse (hypocalcemia) and peripheral atherosclerotic disease (hyperphosphatemia) were the only chronic conditions significantly associated with at least one electrolytic abnormality. Although chronic obstructive 
Table I Baseline Characteristics of Patients $(n=1008) *$

\begin{tabular}{|c|c|c|c|}
\hline Characteristics & $\begin{array}{l}\text { CHUL } \\
(n=476)\end{array}$ & $\begin{array}{l}\text { HDQ } \\
(n=532)\end{array}$ & $\begin{array}{l}\text { Total } \\
(\mathrm{N}=1008)\end{array}$ \\
\hline $\begin{array}{l}\text { Age (mean, SD) } \\
\text { Female }\end{array}$ & $\begin{array}{l}60.3(23.2) \\
289(60.7)\end{array}$ & $\begin{array}{l}70.0(15.2) \\
252(47.4)\end{array}$ & $\begin{array}{l}65.4(19.9) \\
541(53.7)\end{array}$ \\
\hline $\begin{array}{l}\text { Comorbidities } \\
\text { - Coronary artery disease } \\
\text { - Diabetes type I or } 2 \\
\text { - Neoplasia } \\
\text { - Metastasis } \\
\text { - Endocrine disease } \mathrm{a}^{\mathrm{a}} \\
\text { - Chronic renal failure } \\
\text { - Chronic obstructive } \\
\text { - } \text { pulmonary disease }^{\text {- Rheumatic disease }}{ }^{\mathrm{b}} \\
\text { - Malnutrition }\end{array}$ & $\begin{array}{l}72(15.2) \\
85(17.9) \\
74(15.6) \\
7(1.5) \\
104(21.9) \\
78(16.4) \\
40(8.4) \\
24(5.1) \\
7(1.5)\end{array}$ & $\begin{array}{l}177(33.3) \\
151(28.4) \\
254(47.8) \\
85(16.0) \\
133(25.0) \\
164(30.9) \\
96(18.1) \\
21(4.0) \\
11(2.1)\end{array}$ & $\begin{array}{l}249(24.8) \\
236(23.5) \\
328(32.6) \\
92(9.1) \\
237(23.6) \\
242(24.1) \\
136(13.5) \\
45(4.5) \\
18(1.8)\end{array}$ \\
\hline $\begin{array}{l}\text { Charlson index } \\
\text { - } 0-1 \\
\text { - } 2-4 \\
\text { - } 5+\end{array}$ & $\begin{array}{l}185(38.5) \\
117(24.6) \\
174(36.6)\end{array}$ & $\begin{array}{l}42(7.9) \\
120(22.6) \\
370(69.5)\end{array}$ & $\begin{array}{l}227(22.5) \\
237(23.5) \\
544(54.0)\end{array}$ \\
\hline $\begin{array}{l}\text { Medication } \\
\text { - Proton pump inhibitor } \\
\text { - Vitamin D supplements } \\
\text { - Other vitamins } \\
\text { - Calcium supplements } \\
\text { - Furosemide } \\
\text { - Hydrochlorothiazide } \\
\text { - Other diuretics } \\
\text { - Phosphate-binders } \\
\text { d }\end{array}$ & $\begin{array}{l}161(34.0) \\
139(29.3) \\
67(14.1) \\
104(22.0) \\
50(10.5) \\
28(5.9) \\
5(1.1) \\
0(0)\end{array}$ & $\begin{array}{l}290(54.7) \\
242(45.7) \\
78(14.7) \\
199(37.5) \\
104(19.6) \\
50(9.4) \\
20(3.8) \\
20(3.8)\end{array}$ & $\begin{array}{l}45 \mid(44.9) \\
38 \mid(37.9) \\
145(14.4) \\
303(30.2) \\
154(15.3) \\
78(7.8) \\
25(2.5) \\
20(2.1)\end{array}$ \\
\hline Alcohol abuse $e^{e}$ & $63(13.3)$ & $65(12.1)$ & $128(12.7)$ \\
\hline
\end{tabular}

Notes: *All data are presented as $\mathrm{N}(\%)$, unless otherwise specified. ${ }^{\text {aEndocrine }}$ disease: hypo-hyperthyroidism, hypo-hyperparathyroidism, adrenal insufficiency, Cushing disease, Addison disease, multiple endocrine neoplasia (MEN), pheochromocytoma. Diabetes mellitus not included. ' $\mathrm{R}$ heumatic diseases: Rheumatic disease (eg, rheumatoid arthritis, polymyalgia rheumatica) or connective tissue disorder (eg, Lupus, Sjogren syndrome, erythrodermia, other connectivitis). 'Other diuretics: potassium sparing (eg, spironolactone, eplerone, amiloride, triamterene) and acetazolamide. ${ }^{d}$ Phosphate-binders or Phosphate-scavengers: Sevelamer (Renvela, Renagel) and

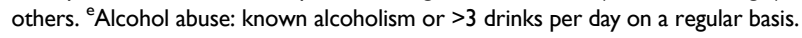

pulmonary disease (COPD), neoplasia, endocrine diseases, osteoporosis and coronary artery disease appeared to be associated with at least one electrolyte abnormality on bivariate analyses, all these associations were lost after fitting our multivariate logistic regression models.

Among the signs and symptoms tested in these models, abdominal pain (hypocalcemia, hyperphosphatemia) and nausea (hypomagnesemia) were associated with at least one abnormal electrolyte. Our analyses confirmed that hypercalcemia is associated with bone pain and hallucinations, but failed to demonstrate an association between hypocalcemia and either paresthesia or musculoskeletal pain. No association was found between abnormal calcium, magnesium or phosphorus and common ED presenting complaints such as palpitations or syncope. Finally, seizures were associated with hypophosphatemia, but no association was found with either hypocalcemia or hypomagnesemia, which are more commonly recognized causes of seizures.

Patients' regular medications were also assessed for potential association with calcium, magnesium or phosphorus imbalance. Our results suggest that furosemide may be an independent predictive factor of hypermagnesemia, as well as vitamin D intake for hypercalcemia.

Among the 1008 tested patients, 3.4\% received a corrective intervention initiated by the emergency physician. This number reaches $6.9 \%$ when adding treatments prescribed by a consultant, leaving $80.5 \%$ of abnormal calcium, magnesium and phosphorus levels untreated. We have identified predictive factors for corrective interventions of electrolyte disorders through multivariate analyses (Table 5 and Supplementary File A4). We found that patients with chronic obstructive pulmonary disease, and those with nausea or vomiting or signs of poor peripheral perfusion were more likely to receive corrective treatment. Although the bivariate analyses showed that chronic kidney disease, peripheral arterial atherosclerotic disease, diabetes, anorexia, tachycardia and an altered level of consciousness predict the need for an intervention on any abnormal electrolyte, these associations disappeared with the subsequent multivariate logistic regression modeling.

Table 2 Prevalence of Abnormal Calcium, Magnesium and Phosphorus Serum Level*

\begin{tabular}{|l|l|l|l|}
\hline & CHUL & HDQ & Total \\
\hline Hypercalcemia & $4.7(3.0-7.2)$ & $2.9(1.7-4.9)$ & $3.8(2.7-5.2)$ \\
Hypocalcemia & $9.9(7.4-13.0)$ & $18.0(14.8-21.6)$ & $14.1(12.1-16.5)$ \\
Hypermagnesemia & $4.6(2.9-7.1)$ & $7.0(5.0-9.6)$ & $5.9(4.5-7.6)$ \\
Hypomagnesemia & $12.5(9.7-15.9)$ & $21.4(18.0-25.2)$ & $17.2(14.9-19.7)$ \\
Hyperphosphatemia & $6.0(4.1-8.7)$ & $12.3(9.7-15.6)$ & $9.3(7.6-11.4)$ \\
Hypophosphatemia & $11.3(8.6-14.7)$ & $11.9(9.3-15.2)$ & $11.6(9.7-13.9)$ \\
\hline
\end{tabular}

Note: *All data are presented as \% (95\% confidence interval). 
Table 3 Most Frequent Presenting Complaints* and Signs in Patients Who Had a Calcium, Magnesium or Phosphorus Serum Level Measurement

\begin{tabular}{|l|l|}
\hline & $\mathbf{n}(\%)$ \\
\hline - Neurologic & a \\
Weakness & $656(65.1)$ \\
Altered mental status & $356(35.3)$ \\
Headache & $215(21.3)$ \\
Gait disturbance & $125(12.4)$ \\
Paresthesia & $97(9.6)$ \\
Seizure & $81(8.0)$ \\
Tremors & $47(4.7)$ \\
\hline - Gastro-intestinal & $44(4.4)$ \\
\hline Nausea/Vomiting & $477(47.3)$ \\
Abdominal pain & $213(21.1)$ \\
Anorexia & $211(20.9)$ \\
Constipation & $193(19.1)$ \\
Diarrhea & $46(4.6)$ \\
\hline - Cardiovascular & $28(2.8)$ \\
\hline Poor peripheral perfusion & $205(20.3)$ \\
Palpitations & $80(7.9)$ \\
Syncope/pre-syncope & $73(7.2)$ \\
Increased work of breathing or desaturation & $66(6.5)$ \\
\hline - Musculoskeletal & $62(6.2)$ \\
\hline Non specific musculoskeletal pain & $232(23.0)$ \\
Bone pain & $213(21.1)$ \\
\hline - Miscellaneous & $41(4.1)$ \\
Weight loss & \\
Fever & $72(7.2)$ \\
Depressive symptoms & $34(3.4)$ \\
Hallucinations & $29(2.9)$ \\
\hline
\end{tabular}

Notes: *Based on the Canadian Emergency Department Information Systems

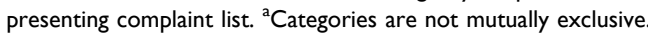

\section{Discussion}

We have identified predictive factors of serum calcium, magnesium and phosphorus abnormalities in the ED. In our cohort composed of 1008 adults for whom emergency physicians felt these tests were indicated, chronic kidney disease (hypocalcemia, hypermagnesemia and hyperphosphatemia), diabetes (hypomagnesemia), alcohol abuse (hypocalcemia) and peripheral atherosclerotic disease (hyperphosphatemia) were associated with at least one calcium, magnesium or phosphorus abnormality. Similarly, we observed that these electrolytic abnormalities were significantly associated with certain presenting complaints (eg, hypercalcemia with bone pain and hallucinations), medications (eg, hypercalcemia with Vitamin D) and certain other test results (eg, hypocalcemia with
Table 4 Protective and Risk Factors of Abnormal Calcium, Magnesium and Phosphorus Serum Level in the Emergency Department $^{\mathrm{a}}$

\begin{tabular}{|c|c|c|}
\hline Abnormality & Risk Factors & $\begin{array}{l}\text { Adjusted OR } \\
(95 \% \mathrm{Cl})\end{array}$ \\
\hline Hypocalcemia & $\begin{array}{l}\text { Respiratory distress } \\
\text { Diuretics (other than } \\
\text { furosemide and } \\
\text { hydrochlorothiazide) } \\
\text { Hyperphosphatemia } \\
\text { Hypomagnesemia } \\
\text { Anti-neoplastic } \\
\text { medication } \\
\text { Long QTc } \\
\text { Chronic kidney disease } \\
\text { Alcohol abuse } \\
\text { Abdominal pain } \\
\text { Hypophosphatemia } \\
\text { Hypermagnesemia }\end{array}$ & $\begin{array}{l}3.3(1.6-6.7) \\
3.2(1.3-8.4) \\
3.0(1.6-5.6) \\
2.6(1.6-4.2) \\
2.3(1.3-4.1) \\
2.0(1.2-3.3) \\
2.0(1.2-3.1) \\
2.0(1.1-3.4) \\
1.9(1.2-3.1) \\
1.9(1.1-3.3) \\
0.3(0.1-0.9)\end{array}$ \\
\hline Hypercalcemia & $\begin{array}{l}\text { Bone pain } \\
\text { Hyperphosphatemia } \\
\text { Vitamin D } \\
\text { Hallucinations } \\
\text { Furosemide }\end{array}$ & $\begin{array}{l}5.7(2.0-15.8) \\
4.6(1.8-11.6) \\
4.1(2.0-8.6) \\
3.9(1.2-13.1) \\
0.1(0.0-0.8)\end{array}$ \\
\hline Hypomagnesemia & $\begin{array}{l}\text { Diabetes } \\
\text { Hypocalcemia } \\
\text { Corticosteroids } \\
\text { Hypophosphatemia } \\
\text { Nausea } \\
\text { Calcium intake }\end{array}$ & $\begin{array}{l}2.7(1.8-3.9) \\
2.3(1.5-3.7) \\
2.2(1.3-3.7) \\
1.8(1.1-3.0) \\
1.8(1.2-2.7) \\
1.6(1.1-2.4)\end{array}$ \\
\hline Hypermagnesemia & $\begin{array}{l}\text { Hyperphosphatemia } \\
\text { Poor extremity } \\
\text { perfusion } \\
\text { Chronic kidney disease } \\
\text { Furosemide } \\
\text { Hypocalcemia }\end{array}$ & $\begin{array}{l}5.9(2.8-12.4) \\
4.3(1.6-11.3) \\
3.0(1.4-6.3) \\
2.9(1.3-6.4) \\
0.2(0.0-0.5)\end{array}$ \\
\hline Hypophosphatemia & $\begin{array}{l}\text { Seizure } \\
\text { Hypocalcemia } \\
\text { Hypomagnesemia } \\
\text { Female }\end{array}$ & $\begin{array}{l}4.0(1.8-8.6) \\
2.5(1.5-4.3) \\
2.0(1.2-3.2) \\
0.6(0.4-0.9)\end{array}$ \\
\hline Hyperphosphatemia & $\begin{array}{l}\text { Phosphate-binders } \\
\text { Hypermagnesemia } \\
\text { Hypercalcemia } \\
\text { Chronic kidney disease } \\
\text { Hypocalcemia } \\
\text { Peripheral vascular } \\
\text { atherosclerotic disease } \\
\text { Abdominal pain } \\
\text { Age }^{\text {b }}\end{array}$ & $\begin{array}{l}4.8(1.4-15.9) \\
4.5(2.1-9.5) \\
4.2(1.5-11.4) \\
4.1(2.2-7.7) \\
2.4(1.2-4.6) \\
2.2(1.1-4.6) \\
1.9(1.1-3.4) \\
0.98(0.96-0.99)\end{array}$ \\
\hline
\end{tabular}

Notes: aStatistically significant associations identified with stepwise selection algorithm of logistic regression model, $\mathrm{P}$ value $<0.05$. Predictive risk factors $\mathrm{OR}>\mathrm{I} /$ Protective effect in italic, $O R<1$. ${ }^{\mathrm{b}}$ Continuous variable. 
Table 5 Protective and Risk Factors of Corrective Interventions for Any Calcium, Magnesium or Phosphorus Abnormality ${ }^{\mathrm{a}}$

\begin{tabular}{|l|l|}
\hline Risk Factors & OR $(\mathbf{9 5 \%} \mathbf{~ C I})$ \\
\hline Calcimimetics & $10.8(1.8-64.6)$ \\
Calcium intake & $2.7(1.6-4.5)$ \\
Poor peripheral perfusion & $2.5(1.3-4.9)$ \\
COPD & $2.0(1.1-3.6)$ \\
Nausea & $1.9(1.1-3.2)$ \\
\hline
\end{tabular}

Notes: Statistically significant associations identified with stepwise selection algorithm of logistic regression model, $\mathrm{P}$ value $<0.05$. Predictive risk factors OR $>\mathrm{I} /$ Protective effect in italic, $O R<1$.

long QTc). Our data did not show any association of syncope or palpitations with calcium, magnesium and phosphorus abnormalities, conditions for which these tests are frequently ordered. These findings may help clinicians make wiser choices and to reduce unnecessary laboratory testing.

Taylor et al, in 2020, also retrospectively studied risk factors for abnormal levels of calcium, magnesium and phosphate in the ED. Their study population was from the ED of a tertiary referral hospital in a metropolitan area and included 1716 patients over a 6-month period. Some risk factors differ between our studies, but corroborate with the following: chemotherapy (stated as antineoplastic medication in our study) for hypocalcemia, diabetes for hypomagnesemia, chronic kidney disease for hypermagnesemia and hyperphosphatemia and seizure for hypophosphatemia. ${ }^{19}$

In 2013, Lindner et al published their work on the demographic and clinical characteristics of hypercalcemia in the ED. Their retrospective cohort study included 14,984 patients for whom serum calcium levels had been electively drawn by ED physicians. They found that malignancy caused hypercalcemia almost half of the time. ${ }^{10}$ Weakness was the most frequent presenting symptom of hypercalcemia, followed by nausea, somnolence and disorientation. In the present study, multivariate analyses showed bone pain to be predictive of hypercalcemia, but not cancer. However, about half of patients with hypercalcemia (48.6\%) did have cancer, compared to $30 \%$ of normo-calcemic patients, and a significant association between hypercalcemia and cancer was found with the bivariate analyses. We conclude that calcium-testing is likely high yield in patients known to have neoplasia presenting with bone pain, weakness or nausea in the ED. Conversely, the possibility of malignancy should be considered in patients found to have hypercalcemia.
Our analyses found hypocalcemia to be related to respiratory distress in multivariate analyses. The main diagnoses for 12 out of 19 patients with respiratory distress were sepsis and pulmonary infections. Our results appear to support previous studies reporting that hypocalcemia correlates with severity of illness in critically ill septic patients. ${ }^{20,21}$

Even though abdominal pain is not considered a classical symptom of hypocalcemia, this association has previously been reported. ${ }^{22}$ The hypothesis underlying this manifestation is that low serum calcium level induces smooth muscle disorders, thus provoking abdominal pain. However, since our cohort was selected among patients who the physician judged may have a calcium and/or magnesium and/or phosphorus serum level abnormality, our results are not generalizable to all ED patients with abdominal pain. Therefore, a systematic search for calcium, magnesium or phosphorus imbalances in all patients with abdominal pain, regardless of comorbidities and other clinical features, would presumably not be cost-effective.

Practice guidelines recommend ordering calcium and magnesium serum levels for new onset seizures. ${ }^{23,24}$ Our results do not seem to support this recommendation, as in our study seizures were only associated with hypophosphatemia. However, the low number of patients with seizures included in our analyses $(n=47)$ precludes any firm conclusion on that matter.

Most of our findings between medications and electrolyte anomalies are consistent with existing literature. Vitamin D increases gut calcium absorption; furosemide enhances renal calcium excretion; phosphate-binders bind to phosphate in the intestinal lumen, thereby decreasing serum phosphate absorption; ${ }^{16}$ the associations are thus intuitive with regards to pathophysiology and support our finding that furosemide is a protective factor against hypercalcemia. In addition, hypocalcemia has been previously described in patients taking spironolactone and anti-neoplastic medication. ${ }^{25}$ However, we did not find a correlate in the literature for the associations found between hypomagnesemia and corticosteroids or calcium intake. Also, the association we found between hypermagnesemia and furosemide use may seem counterintuitive. Indeed, loop diuretics are potential treatments for hypermagnesemia, and causes of hypomagnesemia. ${ }^{18,26}$

Recently, in 2020, Date et al investigated how often ordering calcium, magnesium and phosphorus serum levels changed ED management. They found only 3.0\% $(n=1716)$ of patients tested saw a change in their 
management and stressed for the need to better target patients at risk of abnormal results. ${ }^{9}$ In 1997, Rose et al also published a retrospective study investigating this outcome. They found that, of all the patients tested $(n=1477)$, only $5.4 \%$ had their treatment affected by the results, compared to $6.9 \%$ in our own cohort. In their study, Rose et al demonstrated that three specific groups of patients were at higher risk for needing a corrective intervention: diabetics $\left(\mathrm{Ca},{ }^{+2} \mathrm{PO}_{4}{ }^{-3}\right)$, patients with renal failure $\left(\mathrm{Ca},{ }^{+2} \mathrm{Mg},{ }^{+2} \mathrm{PO}_{4}{ }^{-3}\right)$ and alcoholics $\left(\mathrm{Mg}^{+2}\right)$. They subsequently recommended to limit the ordering of serum levels to these patients unless "confounding factors exist"? Adopting a more comprehensive approach, we tried to identify those confounding factors through multivariate analyses, including not only comorbidities, but presenting symptoms and signs, regular medications and other diagnostic tests. In our own cohort with a high prevalence of multiple comorbidities, predictors of treatment for any imbalance include 1) COPD; 2) patients appearing acutely unwell (poor peripheral perfusion and nausea). Consequently, testing low-acuity patients, without or with few comorbidities, is not likely to be of benefit.

Finally, calcium, magnesium and phosphorus blood level testing was concomitantly performed in $93 \%$ of all patients, while only $12.2 \%$ had more than one electrolytic anomaly. ED doctors might consider testing one electrolyte at a time. However, this study and existing literature show that calcium, magnesium and phosphorus anomalies are often interrelated, particularly phosphate and calcium as they are regulated in concert. ${ }^{16}$ As a result, once predictive factors of any abnormalities are identified in patients, testing concomitantly for calcium, magnesium and phosphorus appears to be a reasonable approach.

\section{Limitations}

Our study has a few limitations. First, although patient medical records are accessible sources of data, their use for research purposes is affected by the significant amount of missing information, and the inconstant legibility of physician notes. Secondly, we have identified risk factors on an ED population that emergency physicians felt were at higher risk for an electrolytic imbalance, based on their clinical judgement. Testing all patients with the risk factors we identified for electrolyte abnormalities (eg, abdominal pain as a predictor of hypocalcemia) may be inappropriate.

Prevalence of calcium, magnesium and phosphorus anomalies in this study are similar to those reported in other studies. However, results should be considered with caution in this matter, since we measured the prevalence in patients who had their levels tested, not the whole ED population.

Furthermore, we mainly focused our attention towards abnormal laboratory values in this study, but it should be emphasized that simply because a test result is normal does not necessarily mean it was unnecessary.

\section{Conclusion}

In summary, chronic kidney disease is a strong predictive factor of calcium, magnesium and phosphorus anomalies in the emergency department, and has already been described as such in the past. Even though ED physicians often test for these anomalies in patients with palpitations and syncope, this study found no associations with electrolyte abnormalities. Most importantly, even though patients regularly present abnormal calcium, magnesium and phosphorus levels in the $\mathrm{ED}$, they rarely require treatment. Based on our results, emergency physicians could reduce the unnecessary use of this type of blood level testing by targeting patients with high-acuity conditions (eg, poor extremity perfusion) and/or significant comorbidities (eg, CKD, COPD). These findings will help us derive and test a clinical decision rule for judicious use of calcium, magnesium and phosphorus serum testing in the ED. Further research is also needed to evaluate the impact of testing and treating these electrolyte imbalances on ED patient-centered health outcomes.

\section{Abbreviations}

$\mathrm{Ca}^{+2}$, calcium; COPD, chronic obstructive pulmonary disease; CHUL, Centre Hospitalier de l'Université Laval; ED, emergency department; HDQ, Hôtel-Dieu de Québec; iv, intravenous; $\mathrm{Mg}^{+2}$, magnesium; $\mathrm{PO}_{4}{ }^{-3}$, phosphorus; po, per os.

\section{Data Sharing Statement}

The datasets generated and analysed during the current study are available in the following repository. https://dataverse. scholarsportal.info/dataset.xhtml?persistentId=doi:10.5683/ SP2/IKKCGQ.

\section{Ethics Approval and Consent to Participate}

The study has been carried out in compliance with the principles of the Declaration of Helsinki. The local ethics committee (CHU de Québec-Université Laval Research Ethics Board) ruled that no formal ethics approval was required for our study (Nagano no. 2017-3104). The decision was based on the Tri-Council Policy Statement, a Canadian guideline 
for the ethical conduct of research involving humans and/or human biological materials (TCPS2, article 2.5). Data collection sheets have also been anonymized in order to respect patient data confidentiality.

\section{Consent for Publication}

Not applicable.

\section{Acknowledgments}

The authors wish to thank Martin Boulé for providing important pharmacological knowledge and David Braganza for proofreading and linguistic revision of the English manuscript.

\section{Author Contributions}

All authors made a significant contribution to the work reported, whether that is in the conception, study design, execution, acquisition of data, analysis and interpretation, or in all these areas; took part in drafting, revising or critically reviewing the article; gave final approval of the version to be published; have agreed on the journal to which the article has been submitted; and agree to be accountable for all aspects of the work. AL, SB, FR and ASP designed the study. SB supervised its conduct. AL, NRM, VM, FPR, CP and MM collected data. AL and DS carried out the statistical analyses. $\mathrm{AL}$ and NRM drafted the initial manuscript. AL, SB, NRM, DS, FR, VM, FPR, CP, MM and ASP revised the manuscript for important intellectual content and approved its final version as submitted. AL assumes full responsibility for the integrity of the manuscript. AL attests that all listed authors meet authorship criteria and that others not meeting the criteria have been omitted.

\section{Funding}

Authors received financial support from l'Association des Médecins d'Urgence du Québec (AMUQ), from le Fonds de Recherche et d'Enseignement du Département de Médecine Familiale et de Médecine d'Urgence de l'Université Laval and from le Fonds d'excellence en Médecine d'Urgence Tim Allen (FEMUTA) de l'Université Laval. These funders played no role in the elaboration of the study, analyses of data or writing of the manuscript.

\section{Disclosure}

Simon Berthelot receives a salary award from Le Fonds de Recherche du Québec-Santé. François Rousseau receives a salary award in evidence-based laboratory medicine from Le Fonds de Recherche du Québec-Santé, Le Ministère de la Santé du Québec, and Le CHU de Québec - Université Laval. All authors declare no other relationships or activities that could appear to have influenced the submitted work. All authors have completed the ICMJE uniform disclosure form. The authors report no other conflicts of interest in this work.

\section{References}

1. Lippi G, Bovo C, Ciaccio M. Inappropriateness in laboratory medicine: an elephant in the room? Ann Transl Med. 2017;5(4):82. doi:10.21037/atm.2017.02.04

2. Li L, Georgiou A, Vecellio E, et al. The effect of laboratory testing on emergency department length of stay: a multihospital longitudinal study applying a cross-classified random-effect modeling approach. Acad Emerg Med. 2015;22(1):38-46. doi:10.1111/acem.12565

3. INESSS. Usage judicieux de 14 analyses biomèdicales. 2014. Available from: http:/www.inesss.qc.ca/fileadmin/doc/INESSS/Webinaires/Juin 2014/INESSS_Rapport-Usage_judicieux_14_analyses_biomedicales. pdf. Accessed December 5, 2016.

4. Choosing Wisely Canada. Recommendations and resources, by speciality. 2020. Available from: https://choosingwiselycanada.org/ recommendations. Accessed December 10, 2020.

5. Choosing Wisely UK. Recommendations for clinicians 2016/18 2019. 2020. Available from: https://www.choosingwisely.co.uk/ i-am-a-clinician/recommendations/\#1572878789681-15fe4ba5-dd0e. Accessed December 10, 2020.

6. Choosing Wisely USA. Promoting conversations between patients and clinicians. 2020. Available from: https://www.choosingwisely. org. Accessed December 10, 2020.

7. Rose WD, Martin JE, Abraham FM, Jackson RL, Williams JM, Gunel E. Calcium, magnesium, and phosphorus: emergency department testing yield. Acad Emerg Med. 1997;4(6):559-563. doi:10.1111/j.1553-2712.1997.tb03578.x

8. Stalnikowicz R. The significance of routine serum magnesium determination in the ED. Am J Emerg Med. 2003;21(5):444-447. doi:10.1016/S0735-6757(03)00097-4

9. Date PA, Smith JL, Spencer WS, de Tonnerre EJ, Yeoh MJ, Taylor DM. Utility of calcium, magnesium and phosphate testing in the emergency department. Emerg Med Australasia. 2020;32 (1):39-44. doi:10.1111/1742-6723.13332

10. Lindner G, Felber R, Schwarz C, et al. Hypercalcemia in the ED: prevalence, etiology, and outcome. Am J Emerg Med. 2013;31 (4):657-660. doi:10.1016/j.ajem.2012.11.010

11. Ministère de la santè et des services sociaux du Quèbec. Rèpertoire quèbècois et système de mesure des procèdures de biologie mèdicale. 2018. Available from: http://publications.msss.gouv.qc.ca/msss/fich iers/2017/17-922-05W.pdf. Accessed April 8, 2019.

12. Johnson K, Suriyaarachchi P, Kakkat M, et al. Yield and cost-effectiveness of laboratory testing to identify metabolic contributors to falls and fractures in older persons. Arch Osteoporos. 2015;10:226. doi:10.1007/s11657-015-0226-3

13. Commissaire à la santé et au bien-être. Apprendre des meilleurs: Étude comparative des urgences du Québec. 2016. Available from: http://www.csbe.gouv.qc.ca/fileadmin/www/2016/Urgences/CSBE_ Rapport_Urgences_2016.pdf. Accessed April 10, 2017.

14. van der Horst A, van de Wijngaart DJ, Scherrenburg J, van Dijk N, Janssens PMW. Practical motives are prominent in test-ordering in the Emergency Department. Clin Chem Lab Med. 2017;55 (10):1523-1529. doi:10.1515/cclm-2016-1092 
15. Verstappen WH, Ter Riet G, Dubois WI, Winkens R, Grol RP, van der Weijden T. Variation in test ordering behaviour of GPs: professional or context-related factors? Fam Pract. 2004;21(4):387-395. doi:10.1093/fampra/cmh408

16. Chang WT, Radin B, McCurdy MT. Calcium, magnesium, and phosphate abnormalities in the emergency department. Emerg Med Clin North Am. 2014;32(2):349-366. doi:10.1016/j.emc.2013.12.006

17. Grafstein E, Bullard MJ, Warren D, Unger B, Group CNW. Revision of the Canadian Emergency Department Information System (CEDIS) presenting complaint list version 1.1. CJEM. 2008;10 (2):151-173. doi:10.1017/S1481803500009878

18. Moe SM. Disorders involving calcium, phosphorus, and magnesium. Prim Care. 2008;35(2):215-237, v-vi. doi:10.1016/j. pop.2008.01.007

19. Taylor DM, Date PA, Ugoni A, et al. Risk variables associated with abnormal calcium, magnesium and phosphate levels among emergency department patients. Emerg Med Australasia. 2020;32 (2):303-312. doi:10.1111/1742-6723.13411

20. Zaloga GP. Ionized hypocalcemia during sepsis. Crit Care Med. 2000;28(1):266-268. doi:10.1097/00003246-200001000-00054

21. Zivin JR, Gooley T, Zager RA, Ryan MJ. Hypocalcemia: a pervasive metabolic abnormality in the critically ill. Am J Kidney Dis. 2001;37 (4):689-698. doi:10.1016/S0272-6386(01)80116-5

22. Schafer AL, Shoback DM, et al. Hypocalcemia: diagnosis and treatment. In: De Groot LJ, Chrousos G, Dungan K, editors. Endotext. South Dartmouth (MA); 2000.
23. Huff JS, Melnick ER, Tomaszewski CA, et al. Clinical policy: critical issues in the evaluation and management of adult patients presenting to the emergency department with seizures. Ann Emerg Med. 2014;63 (4):437-447. doi:10.1016/j.annemergmed.2014.01.018

24. Krumholz A, Wiebe S, Gronseth G, et al. Practice parameter: evaluating an apparent unprovoked first seizure in adults (an evidence-based review): report of the Quality Standards Subcommittee of the American Academy of Neurology and the American Epilepsy Society. Neurology. 2007;69(21):1996-2007. doi:10.1212/01.wnl.0000285084.93652.43

25. Micromedex I Spironolactone. Available from: https://wwwmicromedexsolutions-com.acces.bibl.ulaval.ca/micromedex2/librar ian/CS/29BDF2/ND_PR/evidencexpert/ND_P/evidencexpert/ DUPLICATIONSHIELDSYNC/D8508A/ND_PG/evidencexpert/ ND B/evidencexpert/ND AppProduct/evidencexpert/ND T/eviden cexpert/PFActionId/evidencexpert.DoIntegratedSearch?SearchTerm= spironolactone $\&$ UserSearch Term $=$ spironolactone $\&$ SearchFilter $=$ filterNone\&navitem=searchGlobal\#.

26. Yu ASL Causes and treatment of hypermagnesemia. 2019. Available from: https://www.uptodate.com/contents/causes-and-treatment-ofhypermagnesemia? search $=$ hypermagnesemia\& source $=$ search result\&selectedTitle $=1 \sim 150 \&$ usage_type $=$ default\&display_rank $=1$. Accessed April 23, 2019.
Open Access Emergency Medicine

\section{Publish your work in this journal}

The Open Access Emergency Medicine is an international, peerreviewed, open access journal publishing original research, reports, editorials, reviews and commentaries on all aspects of emergency medicine. The manuscript management system is completely online

\section{Dovepress}

and includes a very quick and fair peer-review system, which is all easy to use. Visit http://www.dovepress.com/testimonials.php to read real quotes from published authors. 